Article

\title{
How to Shape the Employees' Sustainable Work Attitude: The Moderating Effect of Supervisor Attitudes
}

\author{
Hsiang-Yu Ma ${ }^{1}$, Jui-Chung Kao ${ }^{2}$, Rui-Hsin Kao ${ }^{1, * \mathbb{C}}$ and Cheng-Chung Cho ${ }^{1}$ \\ 1 Department of Ocean and Border Governance, National Quemoy University, Kinmen 892, Taiwan; \\ xyma.km@gmail.com (H.-Y.M.); ccho3@yahoo.com (C.-C.C.) \\ 2 Institute of Marine Affairs and Business Management, National Kaohsiung University of Science and \\ Technology, Kaohsiung 80778, Taiwan; jckao@nkust.edu.tw \\ * Correspondence: toptop074@yahoo.com.tw
}

Received: 12 September 2020; Accepted: 8 October 2020; Published: 10 October 2020

\begin{abstract}
Education and training not only play the key role to promote the sustainable ability of employees, but in the establishment of employees' work attitudes as well. Moreover, leaders play an important role in promoting the effectiveness of education and training. The objectives of this study were to explore the effect of the police department's annual subject training on the work attitudes of harbor police. This study also examined the moderating effect of supervisor attitudes on the association between police training effectiveness and police's work attitudes in expectation to more concretely understand the role of supervisor attitudes in the harbor police's annual subject training, to consolidate the good work attitude of the police for sustainability. The frontline police officers of Taiwan's harbor police agency were chosen as the study population. This study adopted the convenience sampling method to conduct the questionnaire survey in August 2019. It requested for the respondents who replied to the questionnaire within 15 days after receiving the questionnaire to be considered as the first respondents. For those who replied to the questionnaire no later than one month were considered as the second respondents. This paper collected a total of 584 questionnaires and 492 were valid. The result of this study showed that education and training had a highly positive effect on the work attitudes of police officers. Moreover, the overall attitudes of supervisors toward police education and training were found to have a significantly positive moderating effect on the association between education and training effectiveness and the police's work attitudes. The results of this study prove the linkage between the effectiveness of education and training and the supervisor attitudes.
\end{abstract}

Keywords: education and training; work attitudes; service-oriented OCB; harbor police; supervisor attitudes

\section{Introduction}

Human capital refers to the skills, knowledge, ability, and experiences of employees working together, which becomes the general capacity of the organization to handle tasks [1,2]. Becker proposed the human capital formation theory in 1964 and analyzed the investment return rate of organizational education and training. Collings and Montgomery [3] divided organizational resources into tangible resources, intangible resources, and organizational capabilities. The term "organizational capabilities" refers to the ability to apply human resources and complicated conversion processes to the operation of each functional department and to control the efficiency of organizational activities. Consequently, organizational capabilities are a source of an organization's competitive advantage [4], while human capital is part of organizational resources as well as the organizational asset [5]. 
One frequently contemplated issue is the method used in cultivating knowledge, techniques, and capabilities for employees in order to increase the organization's competitiveness. Unger, Rauch, Frese and Rosenbusch [6] suggested that human capital can be continually accumulated through learning, formal education, informal on-the-job training, professional training, and other continuing learning channels. It can be found from the literature that a feasible way for human capital accumulation is through education and training including school education or on-the-job training. In fact, on-the-job training is mostly useful to build up an individual's human capital for work. In general, education and training play a critical role in increasing an organization's human capital, both qualitatively and quantitatively. Nowadays, people are more likely to believe that the proper employee training and their suitable experience are required to construct the organizational core competencies [7]. Segovia-Pérez et al. [8] demonstrate that the purpose of education is to ensure that the educated employee obtain the necessary skills, abilities and tools, and to improve their self-perceptions, networking, and motivations. Boldureanu et al. [9] point out that shaping an entrepreneur can be achieved through employee training and emphasize that education plays a key role in the final result of the enterprise. In addition, in order to improve the creativity of employees, organizations are gradually using different education and training methods to cultivate employees [10]. Organizations seek effective leadership, which is one of the most important ways to cultivate outstanding employees [11]. It shows that sustainable education and training have a high degree of connection with leadership.

For the police force, people are the most precious resources and as a result of the dynamic and complicated social phenomena, it is important for the police to make correct judgment as quickly as possible, since criminal tactics evolve quickly. In this case, education and training are essential. Apart from public security and traffic, serving the public has become another core duty of the police in Taiwan in recent years and improving police service quality is a key task of the police agency. According to the interaction theory, Gronroose [12] stated that service quality refers to the experiences shared and created between the customer and the service personnel when rendering a service. Therefore, frontline police officers, who directly interact with the public, play an important role in determining the service quality of the police. Taiwan's harbor police are responsible for maintaining the security of harbors. The harbor police work directly with incoming and outgoing passengers, and therefore, their service to the public significantly influences the overall image of the government. National harbor police officers specifically need to have more interpersonal interactions with people at the point of entry and departure. Therefore, their service effectiveness will directly affect the feelings of domestic and foreign passengers on Taiwan's administrative effectiveness and national image. In summary, based on the perspective of enhancing Taiwan's international reputation, this study is more meaningful than other police sectors. Consequently, it is necessary to examine ways of using education and training, such as annual training, to enhance the organization's human capital for sustainability. This is very important for the harbor police, because they are responsible for border safety and providing passengers, both domestic and international, with high quality services.

Apart from improving employees' professional knowledge and skills by education and training, enhancing employees' positive work attitudes is also important. This is because work attitudes are the behavioral intention of employees for their work and between knowledge, skills, and capabilities, work attitudes are categorized under the capability category. It is known that employees with a positive attitude toward work are more active in applying what they have learnt to their work and incorporating the knowledge or skill into their personal capabilities. This is mostly true for police serving the public, which requires a lot of interpersonal interaction. To improve the public service of the police, it is necessary to strengthen the police organization's identification and motivate police officers to help the public, colleagues, supervisors, or their organization voluntarily based on their job functions. These two measures above can improve satisfaction with police services and ultimately, the overall performance of the organization. Positive work attitudes, such as organizational commitment, professional commitment, and service-oriented organizational citizenship behavior (OCB) [13], are the core human capital of employees. Although employees' work attitudes cover various 
dimensions, employees' organization and work identification, as well as their loyalty, dedication, and willingness to display positive service behavior are often viewed as indicators of work attitudes and a core of human capital that their organization wants to establish. This is also true for the police agency. We can use educational training to build and encourage national harbor police officers to have higher organizational and professional commitments, as well as let police officers have an initiative service-oriented behavior-that being an active and progressive service behavior with enthusiastic and courteous attitudes to provide excellent services to satisfy customers' needs [14]. In general, supervisors play a key role in establishing a good working attitude among police officers in order to improve effective service.

Organizations interested in building their employees' human capital can use systemized and structuralized education and training to improve their employees' work efficiency and efficacy and the result will be beneficial for career development. From the employees' perspective, the investment in education and training demonstrates that their work performance is valued and recognized. Consequently, the result of education and training does not only improve employees' work capabilities but also meets their personal development need. Social exchange theory considers that in social exchange behavior, every individual seeks maximum benefits [15]. To rephrase it, individual behavior is one of the methods of pursuing maximum benefits and least costs [16]. According to the social exchange theory, employees in return may adopt a mutually beneficial approach and have positive work attitudes for the organization [17]. Therefore, education and training are good for improving employees' positive work attitudes.

Several studies have revealed that the organization's huge investment in human resources has a positive impact on the performance of its employees $[18,19]$. Although organization's investment in training improves employees' capabilities; it is not clear if improved employees' capabilities can in turn act on organizational performance or service effectiveness positively and directly. For example, those studies on police in Taiwan $[20,21]$ revealed that even though education and training can improve job performance, work attitudes, and service effectiveness, there are also factors which weaken the effectiveness of education and training. For example, one of the above studies showed that supervisors' attitudes (supportive vs. non-supportive) towards police officers' annual training, their view points on whether training is beneficial for their departmental or organizational performance, and their concerns of whether such training would interfere with the subordinates' work or duty can negatively affect the effectiveness of on-the-job training. Therefore, when we explore how on-the-job training of police could increase their positive working attitude, the attitude of supervisors about the training of subordinates should be taken into consideration. Especially, it is most influenced by Confucian thinking system in Chinese society. It is shaped into close hierarchy relationships, and subordinates have the same attitudes toward supervisors as a son-father relationship. Supervisors are greatly respected and honored. For other Asian countries, the behavior of employees is still greatly influenced by traditional Chinese culture in Hong Kong and Taiwan organizations [22]. Therefore, this study focuses on the supervisor's attitude in Chinese organizations.

Although, there are several studies on police education and training in the world [20,21,23-25], most of them focus on the training results or factors influencing training effectiveness. In other words, none of these studies explored how supervisors' attitudes affect the effectiveness of police annual training, the size of their influence, and the type of influence on the work attitudes of police officers. The effect of the supervisor's attitude on the association between the police's annual training and work attitudes is important for the service quality-oriented harbor police in Taiwan but has rarely been examined. It is therefore a good idea to explore the area and add more information to the research on police annual training.

Based on the above, the main problems of this research include: (1) How important is education and training to build the human resources of Taiwan's international port police? (2) How much influence does education and training have on establishing a good police attitude? (3) How much 
influence does the supervisor's attitude towards police education and training have on the effectiveness of police education and training?

In summary, this is the major reason why this study explored the effect of supervisors on training and the moderator and is also the contribution of this study. Consequently, the assessment of trainees and training effect are not clear nowadays, and it is necessary to have a reasonable standard. The objectives of the present study were to explore the effect of the police department's annual subject training on harbor police's work attitudes, especially in terms of the three work attitudes: (1) organizational commitment, (2) professional commitment, and (3) service-oriented OCB. This study also examined the moderating effect of supervisor attitudes on the association between police training effectiveness and police work attitudes in order to have better understanding on the role of supervisor attitudes in the harbor police's annual subject training.

\section{Literature Review and Hypothesis Development}

\subsection{Education, Training Implications and Effectiveness Evaluation}

Robbins [26] stated that education and training constitute a type of learning experience that leads to relatively durable changes in people's ability to produce better work performance. McGehee and Thayer [27] suggested that education is about cultivating general knowledge and skills, including professional knowledge, techniques, and adaptability to the living environment, for an individual. As for training, it refers to activities of companies or organizations for improving their employees' task implementation-related knowledge, techniques, attitudes or for developing problem-solving capabilities [28]. Based on the regular training purposes of Taiwanese police officers, it is possible for them to have both education and training functions at the same time. Therefore, this study combined "education" and "training" into "educational training", and defined it as follows: educational training is to incubate employees' knowledge, skills, attitudes, habits and problem-solving capabilities, to stimulate employees' maximum potential, and the planned training activities in order to respond to the development of current and future organizations and duty. Taiwan's police can be on-the-job education and training given by members of the organization or off-the-job training given by external agencies or suppliers. In this study, the term "annual subject training" is part of the training.

In terms of education and training effect evaluation, it is about systemically collecting information for a specific training project. Bushnell [29] suggested that the effectiveness of education and training comprises short-term output and long-term outcome. Organizations use education and training to help their employees meet the acquired knowledge and skills, which results in improved work performance in the short term. In the long term, it will improve customer satisfaction and the organization's overall productivity. Therefore, Bushnesll's definition of "output" is similar to the level 1 (reaction), level 2 (learning), level 3 (behavior), and level 4 (results) evaluation of the four-level training evaluation model of Kirkpatrick [30,31]. In Kirkpatrick's model, the reaction level is about evaluating trainees' perception of various aspects of education and training activities, including lecturers' expertise, training contents, teaching material preparations, training environments, and other hardware satisfaction. The learning level is about whether the trainees comprehensively understand the training contents. The behavioral level is about whether the trainees apply the newly acquired knowledge and skills to their behavior and work. It is used to determine the effect of transferring the learning results to the task performance. The level of results explores the effect of education and training on organizational performance [32]. The necessity and feasibility of the result layer of Kirkpatrick's evaluation model have frequently been challenged because of the complicated and difficult-to-conduct evaluation of the result level (e.g., changes in the organization's effectiveness by an education and training activity), trainers' lack of familiarity with the evaluation system, long time interval between the end of training and the display of the outcome, and the assorted factors influencing the training [33,34]. To make up for this deficiency, the study of Chen and Wang [31] only adopted those three levels proposed by Kirkpatrick, such as reaction, learning and behavior, and defined the reaction level as the "training satisfaction degree", the learning 
level as the "personal ability improvement degree", and the behavior level as the "work application degree". In addition, these aforesaid levels were combined as the "educational training effectiveness", and such study has come out with excellent results. Based on this idea, the methods of measuring police officers' educational training effectiveness applied in the present study are in accordance with Chen and Wang [31].

\subsection{Taiwan Police's Annual Training}

Police annual training is a specific term used by the police organization and it is the primary measure employed for human resource development in the police force. The core of Taiwan's police job skills education and training is annual training that is organized by the police department at all levels. The current operating model is that the National Police Agency is responsible for the planning, supervision and assessment of national training for police officers, and the training program of municipality and county (city) is for execution and testing. The purpose is: in order to maintain police discipline, physical fitness and enrich practical knowledge for police officers, police institutions shall implement regular training to meet the requirements of the social environment and work, as well as effectively execute police duties [35]. Therefore, the regular training of Taiwanese police officers is mainly focused on the specific requirements of various duties (such as criminal, administrative, traffic, national harbor, etc.) to design the contents of educational training. Subject training is comprised of moral education, professional knowledge, laws and regulations, and attitudes for duty performance. Technical training consists of physical training, skills for performing the duty, and techniques for using weapons and shooting. For the subject part, each police unit should give officers an eight-hour lecture every quarter and the lecture should be on the required subjects. In addition, each police agency can arrange lectures based on his/her special need. For example, the harbor police agency could focus on helping police officers to develop identity-related and ID-inspection-related capabilities. In addition, career planning, psychological counseling, financial investment, and other self-development topics can also be added to the lectures [20]. In general, annual subject training covers the following areas: (1) duty-related legal literacy, knowledge, and service attitudes; (2) professional competencies for their specific type of work; (3) self-development courses for broadening the vision, increasing professional competencies, and gaining a sense of achievement.

In summary, police training is mainly focused on the professional knowledge of police enforcement, managing their duty or controlling task. Therefore, the course mainly includes professional knowledge, managerial ability and self-inspiration in order to build up the professional function of police officers, develop a positive working attitude, and further improve the effectiveness of serving the people. It also responds to the high expectations of people to the administrative performance of public departments and good service. The police department must boost the professional knowledge of police officers and at the same time, develop a good working attitude of the basic level of colleagues in order to implement the various police tasks and meet the service expectation of the people. It cannot be neglected in the Taiwan police training course to improve the managerial ability and self-inspiration of police officers.

In addition to the situation specified above, many studies (e.g., [20,21]) also found the following appearances about on-the-job training of Taiwan police: (1) no assessment for training requirement; (2) the effect of training is affected by the attitude of relevant personnel; (3) the assessment of trainees and training performance are unclear. All the relevant studies specified above revealed that assessment is important for regular training performance. The assessment of requirement should be planned in the early stage of training. Furthermore, in the study of Yen [36], it discovered that the difficulties of regular training for police officers are as follows: training work has not yet been supported by supervisors of institutions, the teaching resource, training method is not diversified, cannot assess the training need and has not yet conducted a further tracking and overall systematic assessment of the actual effectiveness for implementing regular training. Therefore, the senior unit for planning, supervising and assessing police training is necessary for assessment implementation. For this reason, this study assessed the effectiveness of the training and showed the importance and contribution of 
this study. Besides, Huang [37] demonstrated that the attitude of most supervisors of Taiwan's basic level police do not support the training. At the same time, this affects police officers who do not pay enough attention to the training. Therefore, it is a very important topic to study how the planning of training could be modified in order to improve the support of supervisors, as well as the willingness and motivation of police officers in attending the training.

In summary, the shortcomings of Taiwan's police training may be caused by culture and organizational leadership. The police unit is full of a performance-oriented culture; hence, whoever solves big cases has a better chance for promotion. Leaders of the organization always think that if police officers receive on-the-job training, it will affect their normal tasks. Besides, police officers always feel that the training is of no benefit to their job, especially if it does not enhance their promotion. Therefore, it is important that the connotation of the job design and the contents of on-the-job training complement each other, and there should be an assessment system.

\subsection{Association between Education, Training Effectiveness and Employees' Work Attitudes}

Organizational education and training improve employees' knowledge and skills for performing job-related tasks and assist employees in developing correct work attitudes. For example, Huang [38] stated that education and training enable corporate employees to build positive work attitudes and improve their service quality. According to Huang [38], it found that enterprises with better training performance have better effects as specified above compared to those with worse performance. The key success factors include setting up a training specific unit, having trainees with better performance, implementing the assessment of training requirements, as well as transferring profound and extensive training.

Previous studies have also revealed that for organizations providing their employees with education and training opportunities, the employees' organizational or professional commitment [39,40], work motivation, and work satisfaction will increase $[38,40]$. Furthermore, some researchers suggested that education and training help employees to better understand their job and gain a sense of responsibility for and satisfaction with their duties [41]. Therefore, the working attitude of staff members participating in the training could be improved.

Johlke [42] showed that education and training improve sales agents' active listening and critical skills for selling products, handling disputes, coordinating among parties, and carrying out inspection. These improvements in turn perfect employees' work performance. It was found that the education and training provided by companies or organizations are beneficial for organizational cohesion and employees' professional commitment. For example, the study of Chen and Kao [43] pointed out that the duty of the police does not only include policing, but also entails enhancing the service provided to people in order to maintain a good relationship with them. Therefore, the job of police administration must keep pace with the times. Police officers are expected to have the correct work value and be highly committed to the organization in order to improve the job achievements of the police. In addition, Kao [44] found that if supervisors could arouse the thought of police officers, inspire their aspirations and provide prospection of the police organization, their commitment to the organization could be increased and they could show more organizational citizenship behavior (OCB) [45]. Furthermore, increasing the professional commitment of police officers could also increase OCB [43]. Although there are multiple indexes for positive working attitude, commitment to organization, professional commitment and OCB are very important in increasing the working performance of the police and the core labor resource that the Taiwan police department wants to establish, according to studies about the working attitude of the police specified above. Moreover, according to the study of Kao [46], if police officers place emphasis on recognizing support from the organization, especially support from their supervisors, there will be an increase in their proactive willingness OCB of serving citizens. Hung [21] showed that it could help police officers to increase organizational commitment and arouse them in providing more $\mathrm{OCB}$, if the leaders could stimulate their subordinates to find proper approaches to solving problems and facing challenges. Additionally, it could clearly elaborate the target of the organization and adequately express the prospection of the organization, explain the roles of staff members correctly, 
establish a fair rewarding system, issue concrete orders, as well as provide a vibrant and joyful atmosphere to the organization. Although the positive working attitude is diverse, the subjects of this study are front line boundary police officers who are responsible for boundary policing and providing services to arriving and departing passengers. Therefore, the organization should put in extra effort to encourage high coherence to the organization of police officers, their highly professional commitment and service-oriented OCB. This study applied the three mentioned factors as the major indexes assessing whether a police officer has a positive working attitude. In summary, if enterprises or organizations provide training, there could be increased cohesion and organizational commitment of the staff. Therefore, for the individual staff, participating in the training could enhance productivity, ability, knowledge and self-efficiency. Besides, by providing training, organizations could pay more attention to the career paths of their staff, and in turn improve the recognition and cohesion of staff members to organizations, bringing about a behavioral change.

Apart from the above studies, some studies on the police and nonprofit organizations also revealed that education and training have a positive effect on employees' work attitudes. For example, the police's annual training can improve their work intention, work capabilities, interpersonal relationship, team spirit, positive police behavior, organizational cohesion, and work ethics [20,21,24,25]. In other words, education and training constitute an important channel for updating the police's knowledge, skills, and concepts. Scholars also consider that providing employees with training opportunities is effective in showing employees that the organization is willing to invest in them [47] and the employees in return would treasure such an opportunity and keep positive work attitudes, e.g., the service-oriented OCB [48].

Altogether, the police agency can use education and training to help the police in applying new knowledge, techniques, and approaches to their work in order to enhance organizational competitiveness or personal work performance [49] and to boost organizational cohesion, professional commitment, or feedback behavior benefiting the organization [38]. At the personal level, employees' education and training participation improves their capabilities and knowledge [38] and self-efficacy [50]. At the organizational level, the offering of education and training opportunities to employees strengthens their organizational or professional commitment [39,40], and the employees will be more willing to work for the organization with what was learnt through education and training [51].

The preface of this study pointed out that from the view of staff, the trainings which the organizations invested in imply that organizations not only respect the jobs of their staff but also affirm and respect the individual development of their staff, especially in terms of knowledge and skills related to the jobs, and self-inspired courses that are unrelated to the jobs. Therefore, the result of training could improve the working ability of staff and satisfy their self-development. Besides, according to the view of social exchange theory, staff members may show a positive working attitude in a mutually beneficial way as would reward their organizations. Therefore, the working attitude of staff may be improved by training. The organizational commitment, professional commitment and organizational citizenship behavior (OCB) explored in this study are the positive working attitude of staff to organizations. According to the studies of scholars (e.g., [51-53]), reciprocal exchange is the main reason why a staff member with high emotional attachment or cohesion to their organization or specialty is willing to spend physical and mental efforts, and continue working for the organization or specialty, and behave actively in a manner that benefits the organization or customers unconditionally. This implies that the attitudes or behavioral tendencies of staff members to their organizations are a result of the encouragement or respect shown by organizations to their staff.

The above research shows that education and training enhance employees' positive work attitudes and, according to the exchange theory, employees would pay back with organizational commitment, professional commitment, and service-oriented OCB. The present study therefore proposed the following three hypotheses:

Hypothesis (H1). Police education and training have a positive effect on employees' organizational commitment. 
Hypothesis (H1-1). Police satisfaction at training has a positive effect on employees' organizational commitment.

Hypothesis (H1-2). Police improvement of an individual's ability has a positive effect on employees' organizational commitment.

Hypothesis (H1-3). Police work application level has a positive effect on employees' organizational commitment.

Hypothesis (H2). Police education and training have a positive effect on employees' professional commitment.

Hypothesis (H2-1). Police satisfaction at training has a positive effect on employees' professional commitment.

Hypothesis (H2-2). Police improvement of individual ability level has a positive effect on the employees' professional commitment.

Hypothesis (H2-3). Police work application level has a positive effect on employees' professional commitment.

Hypothesis (H3). Police education and training have a positive effect on employees' service-oriented OCB.

Hypothesis (H3-1). Police satisfaction at training has a positive effect on employees' service-oriented OCB.

Hypothesis (H3-2). Police improvement of individual ability has a positive effect on employees' service-oriented OCB.

Hypothesis (H3-3). The police performance of actual practice has a positive effect on employees' service-oriented OCB.

\subsection{The Moderating Effect of Supervisor Attitudes on the Association between Education, Training and Work Attitudes}

Attitude refers to an individual's positive or negative values of matters, people, or objects. Engel et al. [54] stated that attitudes are an individual's overall value, positive or negative, toward an object. The term "supervisor attitudes" refers to the supervisor's attitudes toward a subordinate at work.

When an enterprising spirit is introduced to public departments, there will be no need for passive leadership anymore. Instead, there will be a need for a leader who is courageous, responsible, creative and innovative, who can proactively lead subordinates and implement the vision. Since the system of leaders protected by a network of civil servants changes with the times, there must be a change in leadership style from authoritative leaders to mission leaders who train up talents. The study of Sun et al. [55] showed that the police officers' attitude or behavior toward certain duties will result in different performances due to their supervisors' emphasis level for such work. Studies on government departments in Taiwan have shown that most supervisors and trainees do not value or support employee education and training. One major reason is that supervisors are usually reluctant to send their subordinates for training, because they have to deal with work-related concerns or a lack of work force. This situation is very serious among entry-level agencies. The true reason for the ineffective education and training function is that the heads of agencies and the high management in general do not understand personnel cultivation [56]. Therefore, a supportive organization environment is necessary for effective education and training and the term "environment" also includes the supervisors' support for employee training [56]. The situation specified above is commonly found in many studies of Chinese organizations (e.g., [57,58]). This implies that the attitude of supervisors has a certain effect on the training, encouraging staff to achieve specific tasks and effects the faith of their subordinates. In the culture of Chinese organizations, the concept "respecting inferiority" is still deeply entrenched in members. It is because in the Chinese tradition, paternalistic leadership is commonly applied for knowledge transfer, technical coaching, and attitude management [59]. In general, managers with this style have a clear and distinctive leadership style, such as being patriarchal. They do not only include 
a clear and powerful authority but also take care and take account of their subordinate, establishing an exemplary moral leadership. Moreover, Chinese organizations have the culture of high Power Distance as a characteristic [60]. Power Distance is an idea proposed by Prof. Geert Hofstede, a Dutch social psychologist, in the early 1980s, which means: "the expectation and the acceptable scale of power inequality for those individuals with less power in national organizations or institutions" [61] (p. 59). The acceptable scale is bigger, the Power Distance is higher; but on the contrary the Power Distance is lower as well. With this characteristic, subordinates have higher compliance to supervisors. Therefore, the training effect of supervisors on the staff would be more significant in Chinese organizations [59]. Organizational culture, organizational job design, and training are related to personal promotion and development. On-the-job training is also affected by internal and external environmental and organizational factors. Moreover, personal factors are involved such as overloaded tasks, no acting colleagues during the training period, and making it compulsory with choice, etc. However, according to the study about police training specified above (e.g., [20-24]), the support from supervisors plays the most important role in police training. It could be said that if the training of police is respected and supported by the supervisors, many obstructive factors specified above could be greatly reduced. This environment includes support from supervisors to staff attending the training, and whether the attitude of supervisors support the training or not. This will affect the willingness of staff to attend the training [58]. From the view of organizational behavior, the effect of training should include many factors of organizational level, such as organizational culture and atmosphere, organizational target and budget, etc. Existing research and studies have shown that the influence of supervisors' attitudes on the training effectiveness of police officers is huge and direct, and can be considered as the key factor for whether the training will be effective or not. Besides, since emphasis has been on front-line police officers, who have the most frequent and close relationship with supervisors, supervisors have the deepest effect on them. Therefore, this study has taken the attitude of supervisors as a core organizational factor. In addition, in the case of theoretical construction that cannot include various impact variables, this study has not explored other organizational factors.

Basically, the supervisor's attitudes have certain effects (e.g., the ability to and faith on completing a given task) on the education and training of subordinates $[57,58]$. It is very true in Chinese organizations $[62,63]$ known for paternalistic leadership and a superior hierarchical status of supervisors. The latter is a key feature of a typical relationship style in Chinese organizations. Both paternalistic leadership and superior hierarchical status contribute to the high Power Distance of the Chinese organizational culture [60]. Therefore, the effects of supervisors on employee training may be more apparent in the police organizations of Taiwan. As mentioned above, supervisors may be uncertain about their subordinates' participation in the education and training, especially in terms of whether the education and training programs are relevant to the needs of the organization or department and whether the frequency of such training would affect the dispatching of personnel for tasks. Some supervisors may even worry that the training will improve the subordinates' capability, which eventually may threaten their status. If supervisors are positive, they would encourage the employee to participate in such education and training and appoint a deputy for training attendees. This is to enable attendees to concentrate better during the training. However, if supervisors, are reluctant to support training and refuse to coordinate it, the effectiveness of training will be compromised [59]. Therefore, before employee training, it is important to acquire the supervisors' mental support. During employee training, it is important for supervisors to provide their subordinates with work assistance. After employee training, supervisors should accept suggestions from subordinates. In all, it is possible that supervisors are playing a moderating role that either enhances or weakens the association between employees' education, training and work attitudes. The present study proposed the following hypotheses: 
Hypothesis (H4). The supervisors' overall attitudes toward education and training and the attitudes before (H4-1), during (H4-2), and after (H4-3) education and training have a significantly positive moderating effect on the association between education, training and employees' organizational commitment.

Hypothesis (H5). The supervisors' overall attitudes toward education and training and the attitudes before (H5-1), during (H5-2), and after (H5-3) education and training have a significantly positive moderating effect on the association between education and training and employees' professional commitment.

Hypothesis (H6). The supervisors' overall attitudes toward education and training as well as the attitudes before (H6-1), during (H6-2), and after (H6-3) education and training have a significantly positive moderating effect on the association between education and training and employees' service-oriented OCB.

\section{Methodology}

\subsection{Research Framework}

The research framework (Figure 1) consists of two parts. First, it depicts the relationships between education and training effectiveness, and work attitude. Second, this study examined the moderating effects of supervisor attitudes and education and training effectiveness on work attitude.

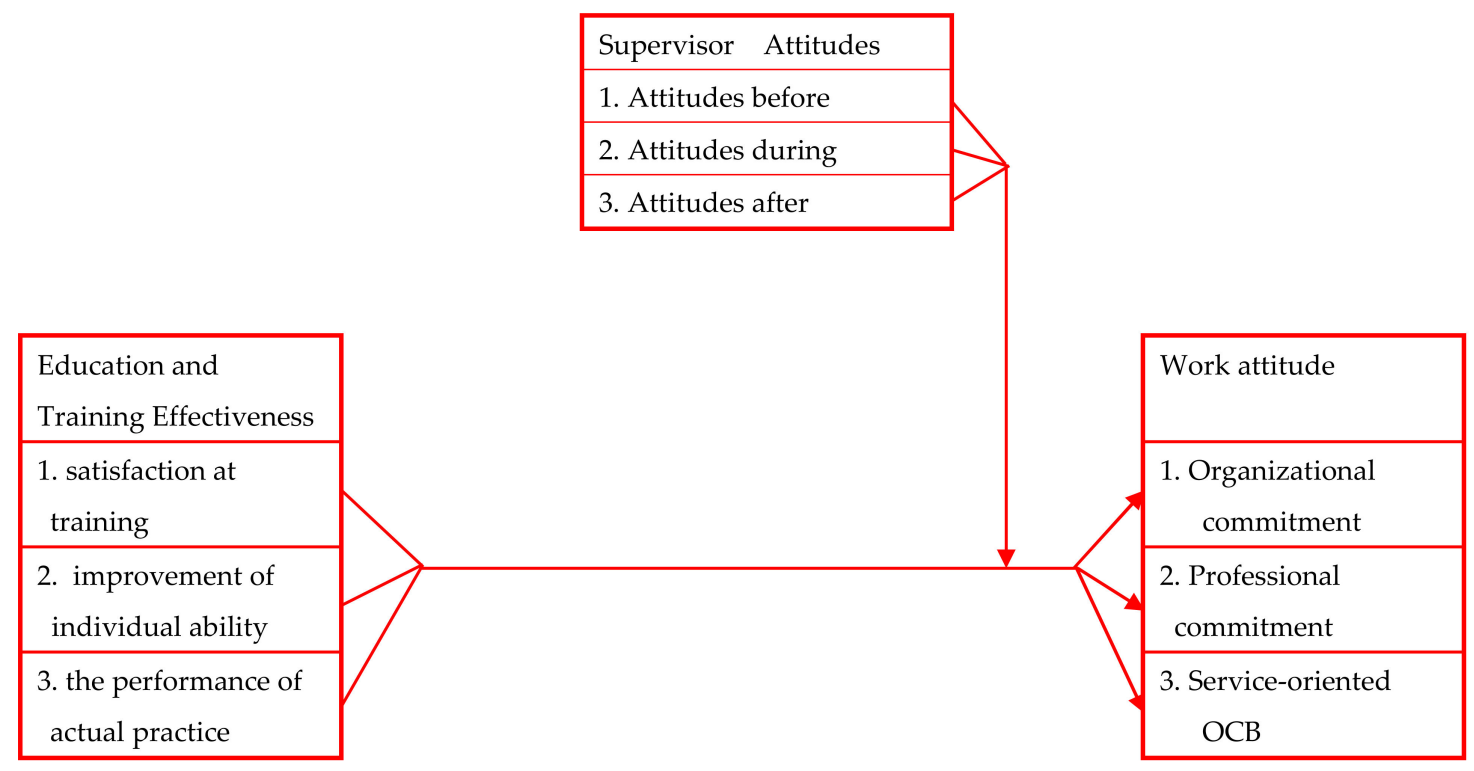

Figure 1. Research model.

\subsection{Analytical Strategies}

Based on the research purpose and hypotheses, the frequency distribution was conducted to understand the distribution of the samples, the mean of the variables, and the scores of the question items. Analyses of Pearson correlation and reliability were performed to understand the correlations among the variables and their Cronbach $\alpha$ coefficient. Due to the fact that multivariate statistical analyses can easily capitalize on chance, CFA (confirmatory factor analysis) was conducted as it fitted the theory testing of the present study. As a theory-driven technique, CFA is argued to be superior to its exploratory counterpart in theory testing, since construction of the model would not be plagued by particular sample data [64]. CFA was conducted accordingly to ensure the stability of the findings and to examine the validity of research variables. Besides, the hierarchical regression analysis was adopted to verify the relationship between the variables. Moreover, Harman's single-factor post-hoc test (cf. [65]) was adopted to prevent the occurrence of common method variance in the data analysis [43] (p. 157). 
The distribution and retrieval of the questionnaires were time consuming because the study subjects were sampled at different places in Taiwan and the long time between the first and last responses implies a possibility of deviation in questionnaire responses. To ensure that the questionnaire properly represents the population, Armstrong and Overton [66] suggested that research should perform a non-response bias test on the collected research data. In the present study, the collected questionnaire responses were divided into two groups depending on the day the responses were made. Those made before the middle day of the one-month questionnaire responding period were grouped as the early-responding group while those made during the later 15 days were the late-responding group. The demographic and research variables of the two groups were compared using the $t$-test (continuous variables) and the Chi-squared test (categorical variables), to determine if there was any response deviation in the retrieved questionnaires of this study.

\subsection{Sampling}

The police in Taiwan are given different types of jobs and tasks and in order to keep the discussion focused, the present study chose frontline police officers of Taiwan's harbor police agency as the study population. The data are collected by questionnaire. It adopts the purposive sampling method. This population comprised sergeants and police officers of the field squadron of 4 harbor police departments. In Taiwan, the active tasks of administrative police mainly include patrol, police raid, guard, and inspection of the duty region. The harbor police are mainly responsible for the security of harbors, goods inspection for arriving and departing passengers as well as the handling of foreign affairs, prevention and inspection of smuggling and illegal immigration or emigration [43]. There are about 1500 national harbor police officers in Taiwan; the field staff of national harbor police officers are mainly responsible for those aforesaid works. In field institutions, the police stations of the harbor police department are the basic units. The ranks in the harbor police station are captain and deputy captain, sergeants and police officers.

This study utilized quite a big study population, but because of the limited work force, time, and budget, as well as considerations of regional characteristics and workload of the study subjects, convenience sampling was adopted. According to the regional characteristics and the business nature of the police units, four harbor police departments were sampled from Taiwan. As for field squadrons of the four harbor police departments, the police officers serve passengers entering and exiting Taiwan, passengers traveling within Taiwan, and harbor operation employees. In general, the work attributes of frontline police officers of these four police departments are similar. In summary, although the subjects of this study serve in four harbors, respectively, their main duty includes security, certificate inspection for arriving and departing passengers, service provision, as well as the prevention of smuggling and illegal immigration or emigration. Therefore, the nature of their task is the same. All police officers from the field squadrons of the harbor police department sampled in the study were asked to fill out questionnaires. Nonetheless, the supervisor and the deputy supervisors of these organizations were excluded from the questionnaire.

\subsection{Data Collection and Informed Consent}

In this study, data collection was carried out using a questionnaire on August 2019 by adopting the convenience sampling method. When implementing the survey, the team of this study visited the workplace of interviewees and explained the research purpose and observations when filling the questionnaire, and interviewees were asked to complete it during their spare time. Interviewees were instructed to return the questionnaire within 15 days after receiving it (considered as the 1st respondent), and within one month at the latest (considered as the 2nd respondent), to complete the questionnaire and return it to team members of this study. Questionnaires returned after one month will be considered as invalid. In this study, 584 questionnaires were collected within one month, and there were 314 copies of the first respondent. After deducting copies with the same answers in every question (such as all answered 1) and questionnaires with lost answers, a total of 492 valid 
questionnaires were returned. Except the supervisor and deputy supervisor for each institution or unit, the rest of the personnel are the test subjects. About 11 to 32 questionnaires were distributed in accordance with the number of personnel for each institution or unit, the average effective recovery ratio was about 71 to $100 \%$, and the total average effective recovery ratio was $84.25 \%$.

To obtain informed consent from the participants, research associates provided a complete explanation of the objectives and procedure of this research. All questions from the participants were answered. The participants were assured that their responses would be confidential and anonymous [46] (p. 11).

\subsection{Measures of Research Variables}

After following Brislin's [67] recommendations with regard to ensuring the accuracy and conceptual equivalence of both the Chinese and English versions, all question items in this study were translated and back translated by bilingual native speakers of both languages. The participants rated items on a 5-point Likert-type scale ranging from 1 (strongly disagree) to 5 (strongly agree) [43] (p. 157).

\subsection{Education and Training Effectiveness}

The effectiveness of the education and training was determined by the employees based on what they perceived rather than the actual conditions. Therefore, the effectiveness assessment here was carried out by each employee independently [68].

The present study used the inventory developed by Chen and Wang [31] and training effectiveness was assessed by these three dimensions: (1) satisfaction at training, (2) improvement of individual ability, and (3) the performance of actual practice. There were 18 questions in total; the present study also took the education and training features of the harbor police into consideration and revised the original inventory. The section "satisfaction at training" covered six questions and this section assessed the trainees' satisfaction. For this part, whether learning had taken place or not was irrelevant. One of the questions was "What are the degree of satisfaction for the course schedule and the textbook content of the regular subject training?" For the section on "improvement of individual ability", there were five questions and this part was used to assess the trainees' learning of the course content; but whether they could apply what they had learnt to their work was irrelevant here. One of the questions was "After having the regular subject training, I can't apply the work attitude and confidence to my work that I'd learnt from such training." As for the section "the performance of actual practice", there were seven questions and they were used to assess the extent to which the trainees could apply the knowledge and skills they had learnt from the education and training to their work. One of the questions was "I can absorb work-related attitude and confidence from the regular subject training." The inventory of Chen and Wang [31] has been verified to have good reliability and validity. Regarding the reliability of the present study's questionnaire, the satisfaction at training had an $\alpha$-coefficient of 0.721; the improvement of individual ability had an $\alpha$-coefficient of 0.908 ; while the performance of actual practice had an $\alpha$-coefficient of 0.744 .

\subsection{Supervisor Attitudes toward Employee Education and Training}

The present study revised the inventory of Liang et al. [59] to adapt to the education and training features of Taiwan's harbor police. The original inventory was developed according to the in-depth interview with five mid- and high-level managers of Liang et al. [59]. The interview was conducted to assess the pre-, mid-, and post-education and training attitudes of supervisors toward employees through interviews with employees to obtain supervisors' attitude before, during and after employees' educational training. There were a total of six questions; two on supervisors' attitudes before employee education and training, such as "Before participating the regular subject training, supervisors can't give me a lot of spiritual encouragement", two on supervisors' attitudes during employee education and training, such as "In participating the regular subject training, supervisors are willing to assist me to handle my works", and two on supervisors' attitudes after employee education and training, such as "After participating the regular subject training, supervisors have taken more of my advice 
on works". The inventory developed by Liang et al. [59] was empirically tested and found to have a good reliability and validity. Regarding the reliability of this study's inventory, the $\alpha$-coefficient of supervisor pre-training attitudes was 0.801 , mid-training attitudes 0.631 , and post-training attitudes 0.822. In summary, this scale asked the respondents two questions before, in the middle and after the training, to measure the attitude of supervisors to police officers during different phases of training. The scores of each type of question (such as before training) will be averaged for analysis, in order to get the scores of recognition for police officers attending the training. The higher scores indicate that the supervisors have more positive attitude to police officers before, in the middle and after the trainings.

\subsection{Organizational Commitment}

To assess the study subjects' organizational commitment level, the present study utilized the organizational commitment inventory of Mowday, Porter and Steers [69] and made some revisions according to the harbor police's education and training features. After the revisions, there were fifteen questions for assessing the three elements of organizational commitment: five on value commitment, including "I will be very proud to tell others that I am a member of this unit", six on effort commitment, including "I have almost no loyalty to the unit I work for now", and four on retention commitment, including "I am very concerned about the future development of this unit". The original inventory of this study was tested by Kao [44] and was found to have a good reliability. As for the reliability of this study's inventory, it was 0.843 for value commitment, 0.705 for effort commitment, and 0.761 for retention commitment.

\subsection{Professional Commitment}

To fit the research subjects in this study, twelve items were adopted and revised from the questionnaire developed by Aranya, Pollock and Amernic [70], to measure the construct of professional commitment. The question items included five items on professional identification, three items on professional involvement, and four items on the commitment to stay in the same profession. Sample items: "For me, the work I do is the best choice." (identification); "In order to work in the police field, I am willing to accept any type of work dispatch." (involvement); "I am very loyal to my current work." (stay in the same profession). A higher score indicates that the participants have a higher level of professional commitment [71]. The reliabilities of the three dimensions were as follows: professional identification (Cronbach's $\alpha=0.841$ ), professional involvement (Cronbach's $\alpha=0.702$ ), and commitment to stay in the same profession (Cronbach's $\alpha=0.706$ ).

\subsection{Service-Oriented OCBs}

To fit the research subjects in this study, thirteen items were used and revised from the questionnaires developed by Payne and Webber [72] and Bettencourt et al. [73] to measure the construct of service-oriented OCBs. The question items included four items on loyalty (such as "I will establish a favorable reputation for the police unit"), five items on service delivery (such as "I will actively improve the police service quality"), and four items on altruism (such as "Even if my work schedule is full, I will still serve the public"). A higher score indicates that the participants showed more service-oriented OCBs. After the pilot study, item analysis was conducted to delete items whose importance ratio failed to reach the level of significance. Twelve question items were used to measure service-oriented OCBs [71]. The reliabilities of the three dimensions were as follows: loyalty (Cronbach's $\alpha=0.702$ ), service delivery (Cronbach's $\alpha=0.755)$, and altruism (Cronbach's $\alpha=0.647$ ).

\subsection{Control Variables}

Based on past research [43,74], the factors of gender, age, educational level, and years of service were used as control variables. Empirical studies showed that education may affect the work performance of police officers [75]. In addition, gender, age and police service seniority will also 
affect the work attitude and behavior of police officers [55]. The purpose of doing so is to verify the aforementioned relationship between an individual's demographic and research variables [43].

Participants rated items on a 5-point Likert-type scale ranging from 1 (strongly disagree) to 5 (strongly agree). A higher score suggests that the respondent agreed more with the research variable.

\section{Results}

\subsection{Basic Analysis}

After deducting copies with same answers in every question (such as all answered 1) and the questionnaire with lost answers from 381 copies that were collected in this study, then a total of 340 valid questionnaires were returned. The sample structure of this study is presented as follows: most of the respondents are male $(91.7 \%)$. The average age was 42.74 years. In average, they had received 13.07 years of education and most of the respondents' service divisions were frontline. The respondents' average service years were 20.92 years. According to the above information, this study's research subjects were mostly males of about 42 years old. On average, they had served in the police department for about 21 years and most of them had either a bachelor's degree or a junior college diploma. The work of Taiwan's harbor police is highly specialized, and the work content is very homogenous (preventing smuggling and illegal immigration). The police turnover here is low and, therefore, the service years of harbor police are longer than those of other administrative police. Lastly, the majority of the police officers in Taiwan have a junior college diploma or above.

Table 1 shows the mean, standard deviation (SD), $\alpha$ coefficient, and between-variable correlation coefficient of the research variables. Table 1 shows that the reliabilities of all the study variables are greater than 0.7 , and there is a positive correlation among the majority of the variables. It shows that the research scale is credible and most of the variables have positive effects. To test whether education and training, organizational commitment, professional commitment, service-oriented OCBs, and supervisor attitudes are different potential constructs, CFA and used LISREL (linear structural relations) estimates (maximum likelihood) were conducted to compare five potential constructs, education and training, organizational commitment, professional commitment, service-oriented OCBs, and supervisor attitudes. The CFA results are shown in Tables 2 and 3, which present evidence that they were different potential constructs. The study shows that measurement variables are not only effective, but independent as well. The results of $t$-test and chi-square test results showed that no significant deviation was found in the demographic and research variables between the two questionnaire responding groups. Table 4 presents a summary of the testing situation of goodness of fit indicators for the overall model, and to sum up the judgment of various indicators, this study's theoretical model recorded a good goodness of fit. This study shows that the measurement is constructed with validity.

Table 1. Descriptive statistics, correlation coefficient, and alpha coefficient.

\begin{tabular}{|c|c|c|c|c|c|c|c|c|}
\hline & \multirow{2}{*}{$\mathbf{M}$} & \multirow{2}{*}{ SD } & \multirow{2}{*}{$\alpha$ Coefficient } & \multicolumn{5}{|c|}{ Research Variables } \\
\hline & & & & (1) & (2) & (3) & (4) & (5) \\
\hline $\begin{array}{l}\text { (1) Education and } \\
\text { training }\end{array}$ & 3.152 & 0.441 & 0.859 & 1 & & & & \\
\hline $\begin{array}{l}\text { (2) Organizational } \\
\text { commitment }\end{array}$ & 2.987 & 0.421 & 0.741 & $0.608^{* * *}$ & 1 & & & \\
\hline $\begin{array}{l}\text { (3) Professional } \\
\text { commitment }\end{array}$ & 3.421 & 0.471 & 0.802 & $0.551 * * *$ & $0.472 * * *$ & 1 & & \\
\hline $\begin{array}{c}\text { (4) Service-oriented } \\
\text { OCBs }\end{array}$ & 3.610 & 0.484 & 0.744 & $0.481^{* * *}$ & $0.481^{* * *}$ & $0.643 * * *$ & 1 & \\
\hline $\begin{array}{l}\text { (5) Supervisor } \\
\text { attitudes }\end{array}$ & 3.301 & 0.785 & 0.801 & $0.557^{* * *}$ & $0.551 * * *$ & $0.485 * * *$ & $0.434 * * *$ & 1 \\
\hline
\end{tabular}


Table 2. Goodness of fit indicators for research variables.

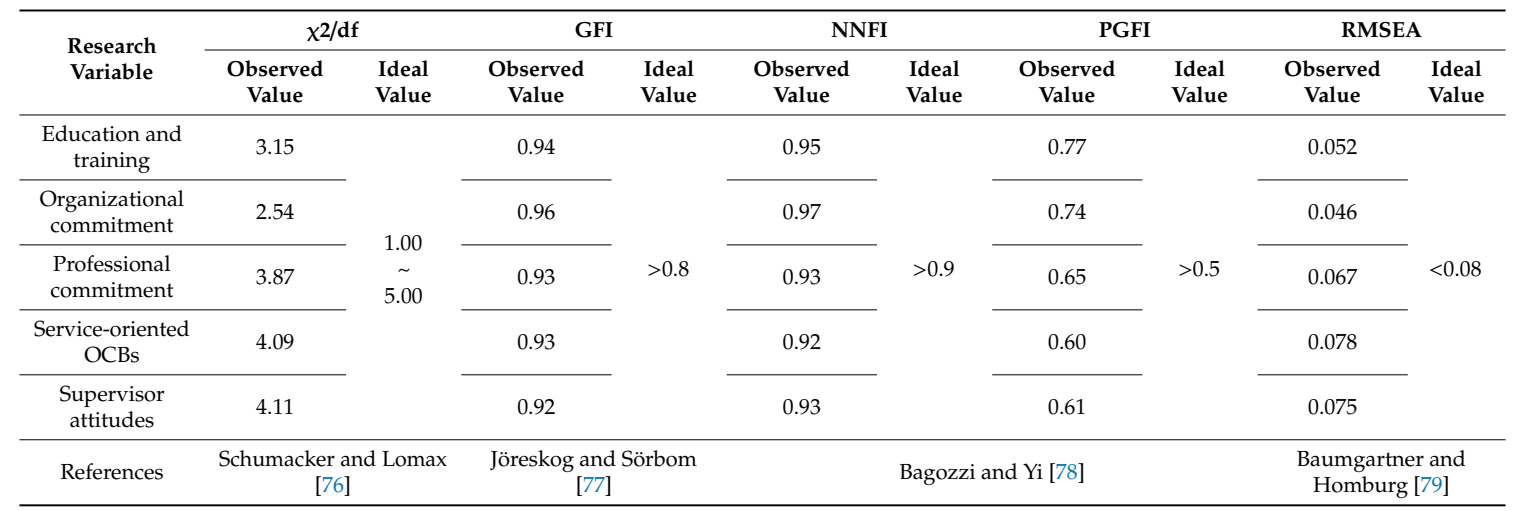

Table 3. Summarized CFA.

\begin{tabular}{|c|c|c|c|c|}
\hline Research Variable & Observed Value & $\lambda$ & $\mathbf{t}$ & AVE \\
\hline \multirow{3}{*}{ Education and training } & Satisfaction at training & 0.80 & 11.24 & \multirow{3}{*}{0.901} \\
\hline & Improvement of individual ability & 0.88 & 12.01 & \\
\hline & The performance of actual practice & 0.74 & 10.24 & \\
\hline \multirow{3}{*}{$\begin{array}{l}\text { Organizational } \\
\text { commitment }\end{array}$} & Value commitment & 0.93 & 15.05 & \multirow{3}{*}{0.745} \\
\hline & Effort commitment & 0.95 & 15.77 & \\
\hline & Retention commitment & 0.84 & 13.65 & \\
\hline \multirow{3}{*}{ Professional commitment } & Professional identification & 0.68 & 7.41 & \multirow{3}{*}{0.811} \\
\hline & Professional involvement & 0.77 & 8.24 & \\
\hline & Commitment to stay in the same profession & 0.89 & 10.12 & \\
\hline \multirow{3}{*}{ Service-oriented OCBs } & Loyalty & 0.91 & 10.77 & \multirow{3}{*}{0.728} \\
\hline & Service delivery & 0.83 & 9.05 & \\
\hline & Altruism & 0.71 & 6.78 & \\
\hline \multirow{3}{*}{ Supervisor attitudes } & Attitudes before & 0.86 & 9.87 & \multirow{3}{*}{0.814} \\
\hline & Attitudes during & 0.94 & 12.01 & \\
\hline & Attitudes after & 0.85 & 8.04 & \\
\hline
\end{tabular}

Note. $\mathrm{n}=492 ; \lambda$, normed factor loadings; AVE, normed average variance extracted.

Table 4. Goodness of fit indicators for overall model.

\begin{tabular}{cccc}
\hline Absolute Fit Measures & Ideal Value & Observed Value & References \\
\hline x $/$ df & $1.00 \sim 5.00$ & 3.41 & Schumacker and Lomax [76] \\
GFI & $>0.8$ & 0.93 & Jöreskog and Sörbom [77] \\
RMSEA & $<0.08$ & 0.069 & Baumgartner and Homburg [79] \\
\hline Incremental Fit Measures & Ideal Value & Observed Value & References \\
\hline AGFI & $>0.8$ & 0.91 & Lu [80] \\
NFI & $>0.9$ & 0.94 & Bagozzi and Yi [78] \\
NNFI & $>0.9$ & 0.93 & Bagozzi and Yi [78] \\
CFI & $>0.9$ & 0.93 & Bentler [81] \\
\hline Absolute Fit Measures & Ideal Value & Observed Value & References \\
\hline PNFI & $>0.5$ & 0.78 & Bagozzi and Yi [78] \\
PGFI & $>0.5$ & 0.70 & Bagozzi and Yi [78]
\end{tabular}




\subsection{Hypothesis Testing}

The Relationship between Education and Training, Organizational Commitment, Professional Commitment, and Service-Oriented OCBs.This paper used hierarchical regression analysis to test the influence of assumption models and control variables on research variables. In this study, when conducting regression analysis, based on the ideas of scholars Hair et al. [82], in order to avoid collinearity problem, it was necessary to determine whether the variance inflation factor (VIF) is less than 10 to ensure that the collinearity problem does not affect the analysis results.

First, as shown in Table 5, it can be observed that model 2's education and training has reached a significant level $(\beta=0.623, p<0.001)$, with a post-adjustment $R^{2}$ of 0.388 and a $\mathrm{F}$ value of $p<0.001$, demonstrating that education and training had a strong explanatory power on organizational commitment; hence, $\mathrm{H} 1$ is supported. In model 3, the effects of "satisfaction at training" and "the performance of actual practice" on organizational commitment are significant $(\beta=0.279, p<0.001$; $\beta=0.388, p<0.001)$. After adjustment, $R^{2}=0.401$ and the F-value $(p<0.001)$ were significant, suggesting that "satisfaction at training" and "the performance of actual practice" had very strong explanatory power on organizational commitment. Therefore, H1-1 and H1-3 are supported, but H1-2 is not supported (improvement of individual ability, $\beta=0.021, p>0.05$ ). In addition, in the segment on control variables, it can be observed from models 2 and 3 , that years of service at the current unit both had a significant influence on organizational commitment $(\beta=-0.248, p<0.05 ; \beta=-0.238, p<0.05)$.

Secondly, as shown in Table 5, it can be observed that model 5's education and training reached a significant level $\left(\beta=0.543, p<0.001\right.$ ), with a post-adjustment $R^{2}$ of 0.311 and an $\mathrm{F}$ value of $p<0.001$, demonstrating that education and training had a strong explanatory power on professional commitment; hence, H2 is supported. In model 6, the effect of "satisfaction at training" $(\beta=0.227$, $p<0.001)$ and "improvement of individual ability" $(\beta=0.439, p<0.001)$ both had a significantly positive impact on professional commitment. After adjustment, $R^{2}=0.337$ and the F-value $(p<0.001)$ is significant, suggesting that "satisfaction at training" and "improvement of individual ability" had very strong explanatory power on professional commitment. Therefore, H2- 1 and H2-2 are supported, but $\mathrm{H} 2-3$ is not supported (the performance of actual practice, $\beta=-0.087, p>0.05$ ). In addition, in the segment on control variables, it can be observed from models 5 and 6 that education level at the current unit both had a significant influence on professional commitment $(\beta=0.156, p<0.01 ; \beta=0.158$, $p<0.01)$.

Furthermore, it can be found from model 8 that education and training had a significantly positive impact on service-oriented OCBs and the explanatory power of the regression model was $48.1 \%$ (Adj. $R^{2}=0.239, p<0.001$ ), which was statistically significant. Hence, H3 is supported. In addition, model 9 showed that "satisfaction at training" and "improvement of individual ability" both had a significantly positive impact on service-oriented OCBs. After adjustment, $R^{2}=0.252$ and the F-value $(p<0.001)$ were significant, suggesting that "satisfaction at training" and "improvement of individual ability" had very strong explanatory power on service-oriented OCBs. Therefore, H3-1 and H3-2 are supported, but H3-3 is not supported (the performance of actual practice, $\beta=-0.026, p>0.05$ ). For the control variables, models 7,8 , and 9 showed that education level at the current unit had a significant influence on service-oriented OCBs. In addition, the statistical results in Table 5 show that VIFs are much smaller than 10 , showing that there are no collinearity problems between variables in this study. 
Table 5. Hierarchical regression analysis (H1-H3).

\begin{tabular}{|c|c|c|c|c|c|c|c|c|c|c|}
\hline \multirow{2}{*}{ Control Variables } & \multicolumn{3}{|c|}{ Model Number } & \multirow[b]{2}{*}{4} & \multirow[b]{2}{*}{5} & \multirow[b]{2}{*}{6} & \multirow[b]{2}{*}{7} & \multirow[b]{2}{*}{8} & \multirow[b]{2}{*}{9} & \multirow[b]{2}{*}{ VIF } \\
\hline & 1 & 2 & 3 & & & & & & & \\
\hline Gender & 0.113 & 0.123 & 0.152 & -0.023 & -0.034 & -0.040 & 0.104 & 0.097 & 0.070 & 1.131 \\
\hline Age & 0.254 & 0.228 & 0.252 & -0.015 & -0.041 & -0.007 & 0.181 & 0.163 & 0.147 & 4.271 \\
\hline Education level & -0.018 & -0.019 & -0.014 & $0.153^{* *}$ & $0.156^{* *}$ & $0.158^{* *}$ & $0.132 *$ & $0.132 *$ & $0.132 *$ & 1.144 \\
\hline Years of service & $-0.268 *$ & $-0.244^{*}$ & $-0.209 *$ & -0.017 & 0.001 & -0.015 & -0.178 & -0.144 & -0.152 & 4.239 \\
\hline \multicolumn{11}{|l|}{ Model independent variables } \\
\hline Education and training & & $0.623 * * *$ & & & $0.543^{* * *}$ & & & $0.481^{* * *}$ & & 1.178 \\
\hline Satisfaction at training & & & $0.279^{* * *}$ & & & $0.227^{*}$ & & & $0.181 *$ & 1.818 \\
\hline Improvement of individual ability & & & 0.021 & & & $0.439^{* * *}$ & & & $0.313^{* *}$ & 1.274 \\
\hline The performance of actual practice & & & $0.388^{* * *}$ & & & -0.087 & & & -0.026 & 1.409 \\
\hline$F$ & 1.03 & $53.07^{* * *}$ & $36.59 * * *$ & $2.66^{*}$ & $38.04^{* * *}$ & $29.26^{* * *}$ & 2.51 & $28.14^{* * *}$ & $19.37^{* * *}$ & \\
\hline Adj. $R^{2}$ & 0.000 & 0.388 & 0.401 & 0.14 & 0.311 & 0.337 & 0.013 & 0.239 & 0.252 & \\
\hline
\end{tabular}

Note. $\mathrm{n}=492$. VIF, normed variance inflation factor. The impact control variables of Modes 1, 4, and 7 are organizational commitment, professional commitment, and service-oriented OCBs, respectively. ${ }^{*} p<0.05 ;{ }^{* *} p<0.01,{ }^{* * *} p<0.001$. 


\subsection{Moderating Effect of Supervisor Attitudes}

In order to measure the moderating effect of the supervisor's attitudes (attitudes before, attitudes during, attitudes after) on education and training and work attitudes (organizational commitment, professional commitment, service-oriented OCBs), reference was made to the study of Baron and Kenny [83]. It is believed that the moderating effect belongs to the independent variable $X$ affecting the dependent variable $Y$ (or relationship between them). From the effect of $Z$ variable (e.g., supervisor attitude), the moderating effect was represented by the interaction of $\mathrm{XZ}$. In the third level, the interaction of education, training and supervisor attitude (education and training $\times$ supervisor attitudes) was submitted [46]. The significance of interaction was applied to determine whether supervisor attitudes have a moderating effect. The result of hierarchical regression analysis is listed in Table 6 . From Table 6 and model 3, it can be observed that supervisor attitudes had a moderating effect on the relationship between education and training and organizational commitment $(\beta=0.422, p<0.001)$; therefore, $\mathrm{H} 4$ is supported. Moreover, from Table 6 and model 4, it was observed that attitudes during training, had a moderating effect on the relationship between education and training and organizational commitment ( $\beta=0.277, p<0.001$ ). Therefore, H4- 2 is supported, but H4-1 and H4-2 are not supported (attitudes before, $\beta=0.123, p>0.05$; attitudes after, $\beta=0.027, p>0.05$ ). Secondly, from Table 6 and model 7 , it can be observed that supervisor attitudes had a moderating effect on the relationship between education and training and professional commitment $(\beta=0.389, p<0.001)$. Therefore, H5 is supported. Moreover, from Table 6 and model 8 , it can be observed that attitudes before and after training, both had a moderating effect on the relationship between education and training and professional commitment $(\beta=0.418, p<0.001 ; \beta=0.283, p<0.001)$. Therefore, H5-1 and H5-3 are supported, but H5-2 is not supported (attitudes during, $\beta=-0.229, p<0.05$, contrary to the original hypothesis).

Lastly, from Table 6 and model 11, it was observed that supervisor attitudes had a moderating effect on the relationship between education and training and service-oriented OCBs $(\beta=0.387$, $p<0.001)$. Therefore, H6 is supported. Moreover, from Table 6 and model 12, it was observed that of attitudes before and after training, both had a moderating effect on the relationship between education and training and service-oriented OCBs $(\beta=0.208, p<0.05 ; \beta=0.249, p<0.05)$. Therefore, H6-1 and H6-3 are supported, but H6-2 is not supported (attitudes during, $\beta=-0.028, p>0.05$ ). In addition, the statistical results in Table 6 demonstrate that VIFs are much smaller than 10. This indicates that there are no collinearity problems between variables in this study. 
Table 6. Hierarchical Regression Analysis (H4-H6).

\begin{tabular}{|c|c|c|c|c|c|c|c|c|c|c|c|c|c|}
\hline \multirow{2}{*}{ Control Variables } & \multicolumn{4}{|c|}{ Model Number } & \multirow[b]{2}{*}{5} & \multirow[b]{2}{*}{6} & \multirow[b]{2}{*}{7} & \multirow[b]{2}{*}{8} & \multirow[b]{2}{*}{9} & \multirow[b]{2}{*}{10} & \multirow[b]{2}{*}{11} & \multirow[b]{2}{*}{12} & \multirow[b]{2}{*}{ VIF } \\
\hline & 1 & 2 & 3 & 4 & & & & & & & & & \\
\hline Gender & 0.113 & 0.123 & 0.150 & -0.024 & -0.023 & -0.034 & 0.99 & 0.097 & 0.104 & 0.097 & 0.086 & 0.079 & 1.055 \\
\hline Age & 0.254 & 0.228 & 0.217 & 0.187 & -0.015 & -0.041 & -0.059 & -0.065 & 0.181 & 0.163 & 0.135 & 0.126 & 4.308 \\
\hline Education level & -0.018 & -0.019 & -0.020 & -0.011 & $0.153^{* *}$ & $0.156^{* *}$ & $0.148^{* * *}$ & $0.151 * * *$ & $0.132 *$ & $0.132 *$ & $0.134 *$ & $0.125 *$ & 1.016 \\
\hline Years of service & $-0.268^{*}$ & $-0.244^{*}$ & -0.187 & -0.187 & -0.017 & 0.001 & 0.071 & 0.070 & -0.178 & -0.144 & -0.096 & -0.088 & 4.288 \\
\hline \multicolumn{14}{|l|}{ Model independent variables } \\
\hline Education and training & & $0.623 * * *$ & $0.263^{* *}$ & $0.277^{* * *}$ & & $0.543^{* * *}$ & $0.194 *$ & 0.154 & & $0.481^{* * *}$ & 0.145 & 0.126 & 2.436 \\
\hline $\begin{array}{l}\text { Education and training } \\
\text { *Supervisor attitudes }\end{array}$ & & & $0.422 * * *$ & & & & $0.389 * * *$ & & & & $0.387^{* * *}$ & & 3.501 \\
\hline $\begin{array}{l}\text { Education and training } \\
{ }^{*} \text { Attitudes before }\end{array}$ & & & & 0.123 & & & & $0.418^{* * *}$ & & & & $0.208^{*}$ & 2.801 \\
\hline $\begin{array}{l}\text { Education and training } \\
{ }^{*} \text { Attitudes during }\end{array}$ & & & & $0.268^{* * *}$ & & & & -0.229 * & & & & -0.028 & 1.804 \\
\hline $\begin{array}{l}\text { Education and training } \\
{ }^{*} \text { Attitudes after }\end{array}$ & & & & 0.027 & & & & $0.283 *$ & & & & $0.249 *$ & 3.601 \\
\hline$F$ & 1.03 & $53.07^{* * *}$ & $51.88^{* * *}$ & $36.99^{* * *}$ & $2.66 *$ & $38.04 * * *$ & $36.04^{* * *}$ & $34.08^{* * *}$ & 2.51 & $28.14^{* * *}$ & $26.88^{* * *}$ & $20.01^{* * *}$ & \\
\hline Adj. $R^{2}$ & 0.000 & 0.388 & 0.438 & 0.445 & 0.14 & 0.311 & 0.349 & 0.409 & 0.013 & 0.239 & 0.288 & 0.277 & \\
\hline
\end{tabular}

Note. $\mathrm{n}=492$. VIF normed variance inflation factor. The impact control variables of Modes 1, 5, and 9 are organizational commitment, professional commitment, and service-oriented

OCBs, respectively. ${ }^{*} p<0.05$; ${ }^{* *} p<0.01 ;{ }^{* * *} p<0.001$. 


\section{Conclusion and Suggestion}

\subsection{Conclusion and Discussion}

Results from the statistical analyses were presented and discussed as follows.

Firstly, education and training had a highly positive effect on police officers' work attitudes, namely, organizational commitment, professional commitment, and service-oriented OCB. Nonetheless, the three sub-dimensions of education and training were affected by different factors. For instance, the police officers' satisfaction with education and training enhanced work attitudes while the personal capabilities were found to affect only professional commitment and service-oriented OCB. Moreover, the work application level was found to be associated with service-oriented OCB only. This result is consistent with the studies of Huang [38], Patrick and Owens [40], and Johlke [42]. That is, educational training can help their employees improve their work motivation and satisfaction, and then establish a work attitude that meets the needs of the organization. This finding shows that police officers were strongly influenced by education and training, especially in terms of training satisfaction; for example, police officers showed a relatively high satisfaction with the annual subject training arrangement and the learning materials. Nonetheless, after training, some of them thought that they still cannot apply the newly acquired skills to improve their work efficiency. It shows that the organization may have conducted training content that employees do not need which prevents employees from improving their work capabilities [84]. From the three sub-dimensions of education and training, Taiwan's police agency should work on not only training satisfaction but also personal capability improvement and work application, such as improving work-related attitudes and confidence, interpersonal relationship and communication skills, as well as relating management and professional knowledge. In addition, it is important to guide police officers to apply what they have acquired from above to their work, especially to help them attain self-development through courses on physical, mental, and spiritual balance. By doing so, police officers can feel that they are valued by their organization and would be encouraged for more interaction and mutually beneficial behavior. In addition, police officers will also be encouraged to express positive work attitudes, especially in terms of service-oriented OCB.

Secondly, the statistical results revealed the positive effect between education level and professional commitment; it is possible that the higher the education, the higher the professional quality and higher professional quality in turn prompts an individual to perform better at his or her expertise, pay more effort than others, improve his or her police expertise, and become more loyal to the police force. In addition, education level also affected the expression of service-oriented OCB. Therefore, a critical question here is whether higher education is better than lower education in eliciting one's sense of social responsibilities. Another possibility is that those with higher education may learn more effectively and be better at applying what they have learnt to their organizations or others. For example, Liao (2007) conducted a meta-analysis of OCB and found that employees with a master's degree expressed significantly more of the altruism dimension of OCB than those with a bachelor's degree. Nonetheless, few studies have examined the association of OCB and education. It also shows that sustainable education is important. Another interesting phenomenon found by the study is that the study subjects' seniority was negatively associated with their organizational commitment. This and related research (e.g., [74]) have considered that service seniority will affect educational training effectiveness as revealed from related research findings. In other words, senior harbor police officers in Taiwan may have a lower value recognition, effort, and loyalty toward their organizations. This shows that police officers with longer service seniority whose coherence to their organization may be reduced by time, as well as their service enthusiasm, which may also decline, may affect the organization's service quality. It deserves the attention of leaders of the national harbor police and staff to make certain improvements. Engelbrecht, Heine, and Mahembe [85] pointed out that to establish a good relationship between leaders and employees, organizations should adopt the appropriate and effective training and development plans. This leads to greater organizational commitment. Therefore, Taiwan's police 
agency should use education and training to enhance the police's dignity and to encourage them to use their capabilities for better work performance, to put more effort into organizational development and success, and to boost their organizational commitment, to consolidate the good work attitude of the police for sustainability.

Lastly, the overall supervisor attitudes toward police education and training were found to have a significantly positive moderating effect on the association between education, training effectiveness and the police's work attitudes, namely organizational commitment, professional commitment, and service-oriented OCB. In terms of the supervisors' attitudes before, during, and after the police education and training, significantly positive moderating effects were found consistently except under two conditions: (1) the pre- and post-training attitudes of supervisors toward the employee on organizational commitment and (2) the mid-training attitudes of supervisors toward the employee on service-oriented OCB. This also revealed that supervisors' attitudes do play a key role in educational training effectiveness. As mentioned in introduction, employees may reciprocate and present positive work attitudes to their organizations in return [17]. The results of this study are similar to those research studies found through the exchange of reciprocal exchanges, which may influence the behavior of subordinates [84]. Therefore, educational training does improve employees' work attitude. This study discovered that it echoes SET's point of view. What is worth noting is that supervisors' mid-training attitudes were found to have a significant effect on police officers' professional commitment. For future studies, it will be interesting to find out whether employees with higher education would prefer greater work autonomy [86].

The interview was conducted to assess the pre-, mid-, and post-education and training attitudes of supervisors toward employees.

\subsection{Theoretical and Practical Implications}

The result of this study includes the following theoretical and practical implications:

Here are the theoretical implications from the literature review and findings of the present study. First, police education and training are important. Several studies have explored the effectiveness of education and training, but only a few have examined the impact from work attitudes. The results of the present study are in agreement with other studies' findings by showing that education and training indeed enhance the knowledge and skills required by the police for implementing their tasks and assisting the police in establishing correct work attitudes. The present study also clarified the effect of different education and training contents on different work attitudes, as well as the effect of differences in police officers' education level and years of service on their education and training effectiveness. We found that although education and training are important for the establishment of a good working attitude for the police officer, different dimensions of education and training have different effects. For instance, the police's satisfaction with education and training has improved their work attitudes. However, personal capabilities were found to only affect professional commitment and service-oriented $\mathrm{OCB}$, while work application level was found to be only related to service-oriented OCB. This finding shows that the police are strongly influenced by education and training, and shows its importance, especially in the section of training satisfaction. Furthermore, this study found that the level of education has a positive effect on professional commitment and service-oriented OCB. The length of service will have a negative impact on the effectiveness of education and training. Again, it shows that education and training are important, and it is highly significant to study it. However, there are few studies to detect the relationship between OCB and education before this. The results of the study added important information to theories related to education and training. Secondly, the present findings also demonstrated the moderating effect of supervisor attitudes, thus helping the academic field to better understand and be more aware of the importance of the effects of supervisor attitudes on education and training. This study also discussed the way to help supervisors to be more positive about employee training, which has rarely been discussed in the literature. Lastly, it is well known that providing employee education and training is important for personnel retention. However, 
the present study also showed that more studies are required on the types of training and education, the better for improving work attitudes.

Here are some practical implications from the present study.

First, the present study shows that good education and training satisfaction constitute the most effective factor in shaping the police's positive work attitudes. Therefore, it is important to understand the needs of the police, to offer suitable courses and to appoint good instructors. With this kind of training and education, police officers would more likely adopt the organization's perspective for viewing and handling various situations, that is, they will be better at making decisions based on the interest of the organization. In addition, police officers will better identify themselves with the organization, do their best for the organization and their work, and positively act for the interest of the organization. Previous studies have shown that supervisors' lack of interest in police officers' education and training and police officers' own lack of interest in participating in training compromise the effectiveness of education and training. Therefore, a key task for the authority is to change the existing education and training plan to improve supervisors' and police officers' willingness and motivation for the annual training. Secondly, when the harbor police organization is providing police training, it is important to ask the supervisors to perform their duties, such as taking care of their subordinates before the training and encouraging them to do their best or asking if work-related assistance is required during their training. Of course, after the training, supervisors should reward these police officers with good work performance. Altogether, the education and training of harbor police should first be targeted at delivering the core value of the organization, that is, informing the trainees that the purpose of the training is to help them complete their tasks and protect and serve the public more effectively. Then, it is important to determine appropriate training plans to improve the expertise of police officers. In addition, the harbor police organization should place emphasis on group collaboration during the education and training in order to prompt their police officers to take responsibilities on their own as much as possible and to serve the interest of the organization or the public.

The present study further revealed that the harbor police's personal capabilities and applications of their learning results to work should be improved. Therefore, for harbor police education and training, it is important to enhance the police's work attitudes, confidence, and interpersonal skills in relation to their work. Apart from focusing on the police's self-management and self-inspiration for improving their work performance, the authority should also allocate more time and budget for police education and training. Police officers should be supported before training, assisted during training, and recognized for their effort after training. Rewarding police for the positive changes induced by education and learning is also a good idea. It is very important to look after junior police officers who have not received much training to enhance the effectiveness of their education and training and to encourage them to express work attitudes that are good for the organization and public [87].

Generally speaking, the future world is changeable and diverse. The training of police officers must be adapted to present-day needs. The police's educational training should strengthen the "soft" part (such as, public service, communication skills, problem solving and planning management), professional skills training and work training, and combine regular training content with actual work to create a learning environment. National harbor police officers are faced with ever-changing challenges. In addition to improving their own abilities, they also need to enhance their competence in work and life through experience sharing, seminars and various workshops. In recent years, the Internet has developed rapidly, and police officers' training courses must keep pace with the times. The best way to implement what we have learnt is to connect training and work as much as possible. This study showed the importance of "supervisors' support"; thus, police supervisors should actively establish a cooperative or supportive organizational culture to motivate police officers to have the willingness to participate in training [88]. Finally, this study finds that the supervisor plays an important role in employee's education and training. How to make leaders function properly, that is how to build sustainable leadership. Employees can be more willing to engage and increase 
work involvement [89]. For instance, by actively listening to employees' opinions and involving employee groups that encompass various work positions and the job areas involved in the process of making decisions [90]. In addition, the literature shows that the empowering employee can enhance employees' identification and willingness of organizational goals [91], which is helpful for establishing employees' higher organizational commitment [92]. Furthermore, to allow employees to have more work participation, employees can communicate with each other through teamwork, and then be responsible for the actions of the organization [93]; by this, employees will help each other more than before, which in turn encourages them to develop more OCBs [92]. This is important for the international harbor police officer who takes service orientation as one of his main tasks. In addition, in order to make leadership sustainable, leaders should provide employees with organizational rewards such as to ensure that they can participate in decision-making, make fair decisions and promote support for education and training. If leaders can provide a role model that can stimulate employees' continuous learning through supporting education and training, they will promote employees' good working attitude.

\subsection{Limitations and Recommendations for Future Research}

This study has certain limitations. Firstly, the major restriction is that the variable of this study cannot include multiple organizational and personal factors, such as organizational culture, organizational leadership, job design, and the personal motivation of attending training, career planning, and job pressure. This study focused on exploring the effect of the attitude of supervisors to police officers attending the training, and the corresponding moderator. Besides, since this study was restricted by time, labor resources, and theoretical construction, all variables were not included. Other organizational and personal factors must be excluded. However, in this study it is believed that these factors are worth studying further in the future, especially the topics related to organizational culture and leadership. Next, the characteristics of the sample: the sample subjects of this study are the front-line harbor police in Taiwan. The nature of their duty is different from common administrative police. Therefore, further studies should be conducted to determine whether the result of this study is applicable to other police organizations. Third, although this study sampled the first-line harbor police officers from the national harbor police officers, the issue of police officers' ${ }^{\prime}$ work attitude should still be understood comprehensively. Therefore, it is suggested that in the future, a comprehensive survey of national harbor police officers at all levels should be conducted, which specifically reflected the relationship between those variables in this study. Fourth, this study is based on the evaluation of education training effectiveness, lacking the "level of results" test in the evaluation model of the educational training effectiveness proposed by Kirkpatrick [30], although this is due to the difficulty and complexity of the evaluation of the results level. However, it is important to discuss the effect of educational training on organizational performance. Moreover, it is suggested that future research can overcome this limitation. Fifth, it is recommended that future studies take into account police officers' positive enthusiasm for educational training, such as to be listed as the moderator or intervening variables, to understand the role that it played in the relationship between educational training and work attitude; or, as the control variables, so that this factor will not interfere with the research results. Sixth, the supervisors' attitudes were statistically considered among group-level variables. It is suggested that the follow-up research can be tested by the statistical method of hierarchical linear modeling to specifically reflect the relationship between the variables. Lastly, the study should apply longitudinal analysis to conduct a model check in order to avoid the shortcoming of cross-sectional analysis that collects data in a specific time and location.

Author Contributions: Conceptualization, H.-Y.M. and R.-H.K.; Methodology, J.-C.K.; Software, C.-C.C.; Validation, H.-Y.M. and J.-C.K.; Formal Analysis, R.-H.K.; Investigation, H.-Y.M.; Resources, C.-C.C.; Data Curation, J.-C.K.; Writing-Original Draft Preparation, H.-Y.M. and R.-H.K.; Writing-Review \& Editing, C.-C.C.; Visualization, J.-C.K.; Supervision, H.-Y.M.; Project Administration, R.-H.K.; Funding Acquisition, R.-H.K. All authors have read and agreed to the published version of the manuscript. 
Funding: This research received no external funding.

Conflicts of Interest: The authors declare no conflict of interest.

\section{References}

1. Fitz-enz, J. The ROI of Human Capital, Measuring the Economic Value of Employee Performance; Amacom: New York, NY, USA, 2000.

2. Lim, L.L.K.; Chan, C.C.A.; Dallimore PLL, K.; Chan, C.C.A.; Dallimore, P. Perception of human capital measures: From corporate executives and investors. J. Bus. Psychol. 2009, 25, 673-688. [CrossRef]

3. Collings, D.J.; Montgomery, C.A. Corporate Strategy: Resources and the Scope of the Firm; McGraw-Hill: Boston, MA, USA, 1997.

4. Afshari, L.; Young, S.; Gibson, P.; Karimi, L. Organizational commitment: Exploring the role of identity. Pers. Rev. 2019, 49, 774-790. [CrossRef]

5. McGuire, D.; Garavan, T.N.; O'Donnell, D.; Murphy, C. Continuing professional development in the Irish legal profession: An exploratory study. Contin. Prof. Dev. 2001, 4, 21-46.

6. Unger, J.M.; Rauch, A.; Frese, M.; Rosenbusch, N. Human capital and entrepreneurial success: A meta-analytical review. J. Bus. Ventur. 2011, 26, 341-358. [CrossRef]

7. Scott, G.; Leritz, L.E.; Mumford, M.D. The effectiveness of creativity training: A quantitative review. Creat. Res. J. 2004, 16, 361-388. [CrossRef]

8. Segovia-Pérez, M.; Laguna-Sánchez, P.; de la Fuente-Cabrero, C. Education for Sustainable Leadership: Fostering Women's Empowerment at the University Level. Sustainability 2019, 11, 5555. [CrossRef]

9. Boldureanu, G.; Ionescu, A.M.; Bercu, A.M.; Bedrule-Grigorut, M.V.; Boldureanu, D. Entrepreneurship Education through Successful Entrepreneurial Models in Higher Education Institutions. Sustainability 2020, 12, 1267. [CrossRef]

10. Amabile, T.M.; Pratt, M.G. The dynamic componential model of creativity and innovation in organizations: Making progress, making meaning. Res. Organ. Behav. 2016, 36, 157-183. [CrossRef]

11. Asif, M.; Qing, M.; Hwang, J.; Shi, H. Ethical Leadership, an effective Commitment, Work Engagement, and Creativity: Testing a Multiple Mediation Approach. Sustainability 2019, 11, 4489. [CrossRef]

12. Gronroos, C. A service ouality model and its marketing implications. Eur. J. Mark. 1984, 18, 36-44. [CrossRef]

13. Luu, T.T. Service-oriented high-performance work systems and service-oriented behaviours in public organizations: The mediating role of work engagement. Public Manag. Rev. 2019, 21, 789-816. [CrossRef]

14. Hogan, J.; Hogan, R.; Busch, C.M. How to measure service orientation. J. Appl. Psychol. 1984, 69, 167-173. [CrossRef] [PubMed]

15. Blau, P.M. Exchange and Power in Social Life; Wiley: New York, NY, USA, 1964.

16. Molm, L.D. Coercive Power in Social Exchange; Cambridge University Press: New York, NY, USA, 1997.

17. Eisenberger, R.R.; Huntington, S.H.; Sowa, D. Perceived organizational support. J. Appl. Psychol. 1986, 71, $500-507$. [CrossRef]

18. Katou, A.A. Measuring the impact of HRM on organizational performance. J. Ind. Eng. Manag. 2008, 1, 119-142. [CrossRef]

19. Stanton, P.; Nankervis, A. Linking strategic HRM, performance management and organizational effectiveness: Perceptions of managers in Singapore. Asia Pac. Bus. Rev. 2011, 17, 67-84. [CrossRef]

20. Lee, S.K. A study on police annual training status and effective assessment. J. Police Manag. 2011, 7, $223-237$. (In Chinese)

21. Hung, K.P. To perfect our country's police training, on-job. Natl. Taiwan Police Coll. Bull. 2014, 5, 51-81. (In Chinese)

22. Resick, C.J.; Martin, G.S.; Keating, M.A.; Dickson, M.W.; Kwan, H.K.; Peng, C. What Ethical Leadership Means to Me: Asian, American, and European Perspectives. J. Bus. Ethics 2011, 101, 435-457. [CrossRef]

23. Annell, S.; Lindfors, P.; Sverke, M. Police selection-Implications during training and early career. Polic. Int. J. Police Strateg. Manag. 2015, 38, 221-238. [CrossRef]

24. Alain, M.; Crête, C. Continuous training as a subject of negotiations in public and private policing: Managing security expertise in a changing environment-An exploratory study. Polic. Int. J. Police Strateg. Manag. 2009, 32, 75-91. [CrossRef] 
25. Feltes, T. Community-oriented policing in Germany: Training and education. Polic. Int. J. Police Strateg. Manag. 2002, 25, 48-59. [CrossRef]

26. Robbins, S.P. Foimdmental of Mangement; Prentice Hall: Englewood Cliffs, NJ, USA, 2004.

27. McGehee, W.; Thayer, P.W. Training in Business and Industry; Wiley: New York, NY, USA, 1961.

28. Dessler, G. Human Resource Management, 8th ed.; Prentice-Hall: Englewood Cliffs, NJ, USA, 2000.

29. Bushnell, D.S. Input, process, output: A model for evaluating training. Train. Dev. J. 1990, 44, 41-43.

30. Kirkpatrick, D.L. Technique for evaluating training programs. Train. Dev. J. 1959, 13, 3-9.

31. Chen, M.S.; Wang, Y.T. Input-process-effectiveness: A model for evaluating training. J. Hum. Resour. Manag. 2006, 6, 75-99.

32. Kirkpatrick, D.L.; Kirkpatrick, J.D. Evaluating Training Programs: The Four Levels; Berrett-Koehler: San Francisco, CA, USA, 2006.

33. Youndt, M.A.; Snell, S.A.; Dean, J.W.; Lepak, D.P. Human resource management, manufacturing strategy, and firm performance. Acad. Manag. J. 1996, 39, 836-866.

34. Warr, P.A.C.; Birdi, K. Predicting three levels of training outcome. J. Occup. Organ. Psychol. 1999, 72, 351-375. [CrossRef]

35. Lin, S.F. A research on the related factors and effect on routing police training in Taiwan. Police Sci. $Q$. 2009, 39, 137-159. (In Chinese)

36. Yen, T.L. Police Organization Development and Service Strategy: Police Human Resource Development. 2015. Available online: http://www.google.com.tw/url.2015/8/31 (accessed on 5 September 2020).

37. Huang, F.Y.; Lin, C.C. The study of improving training programs for policemen in Taiwan. Law Enforc. Rev. 2008, 4, 1-24. (In Chinese)

38. Huang, T.C. The relation of training practices and organizational performance in small and median size enterprises. Educ. Train. 2001, 43, 437-444. [CrossRef]

39. Finegold, D.; Levenson, A.; Buren, M. Access to training and its impact on temporary workers. Hum. Resour. Manag. J. 2005, 15, 66-85. [CrossRef]

40. Owens, P.L. One more reason not to cut your training budget: The relationship between training and organizational outcomes. Public Pers. Manag. 2006, 35, 163-171. [CrossRef]

41. Ramirez, A.A. Formal training, temporary contracts, productivity and wage. Oxf. Bull. Econ. Stat. 1994, 56, $151-170$. [CrossRef]

42. Johlke, M.C. Sales presentation skills and salesperson performance. J. Bus. Ind. Mark. 2006, 21, 311-319. [CrossRef]

43. Chen, C.H.; Kao, R.H. Work values and service-oriented organizational citizenship behaviors: The mediation of psychological contract and professional commitment: A case of students in Taiwan Police College. Soc. Indic. Res. 2012, 107, 149-169. [CrossRef]

44. Kao, R.H. A study on the relationship between transformational leadership and organizational climate: Using HLM to analyze context effects of police organization. Glob. Adv. Res. J. Manag. Bus. Stud. 2015, 4, 087-115.

45. de Geus, C.J.C.; Ingrams, A.; Tummers, L.; Pandey, S.K. Organizational citizenship behavior in the public sector: A systematic literature review and future research agenda. Public Adm. Rev. 2020, 80, 259-270. [CrossRef]

46. Kao, R.H. Task-oriented work characteristics, self-Efficacy, and service-oriented organizational citizenship behavior: A cross-level analysis of the moderating effect of social work characteristics and collective efficacy. Pers. Rev. 2017, 46, 718-739. [CrossRef]

47. Wayne, S.J.; Shore, L.M.; Liden, R.C. Perceived Organizational Support and Leader-Member Exchange: A Social Exchange Perspective. Acad. Manag. J. 1997, 40, 82-111.

48. Guzzo, R.A.; Noonan, K.A.; Elron, E. Expatriate managers and the psychological contract. J. Appl. Psychol. 1994, 79, 617-626. [CrossRef]

49. Kirkpatrick, D.L. Great ideas revisited: Techniques for evaluation training programs. Train. Dev. 1996, 50, 54-60.

50. Mann, S.; Robertson, I.T. What should training evaluations evaluate? J. Eur. Ind. Train. 1996, $20,14-20$. [CrossRef]

51. Meixner, W.F.; Bline, D.M. Professional and job-related attitudes and the behaviors they influence among government accountants. Account. Audit. Account. J. 1989, 2, 8-20. [CrossRef]

52. Bateman, T.S.; Organ, D.W. Job satisfaction and the good soldier: The relationship between affect and 'citizenship'. Acad. Manag. J. 1983, 26, 587-595. 
53. Greenfield, A.C., Jr.; Norman, C.S.; Wier, B. The effect of ethical orientation and professional commitment on earnings management behavior. J. Bus. Ethics 2008, 83, 419-434. [CrossRef]

54. Engel, J.E.; Blackwell, R.D.; Miniard, P.W. Consumer Behavior, 8th ed.; Dryden Press: Chicago, IL, USA, 1995.

55. Sun, I.Y.; Cretacci, M.A.; Wu, Y.; Jin, C. Chinese police cadets' attitudes toward police role and work. Polic. Int. J. Police Strateg. Manag. 2009, 32, 758-780. [CrossRef]

56. Chang, R.P.; Ho, L.H. Base on the Training Needs Assessment Theories to Analyze the Advanced Training and Studying Strategies for Civil Servants. J. Hum. Resour. Manag. 2003, 3, 81-111. (In Chinese)

57. Bandura, A. Social Learning Theory; Prentice Hall: Englewood Cliffs, NJ, USA, 1977.

58. Axtell, C.M.; Parker, S.K. Promoting role breadth self-efficacy through involvement, work redesign and training. Hum. Relat. 2003, 56, 113-131. [CrossRef]

59. Liang, H.M.; Kao, R.H.; Tu, C.C.; Chin, C.C.; Chung, W.C. The influence of education and training on work attitudes and the moderating effect of supervisor attitudes: Examining Chinese employees. Soc. Indic. Res. 2014, 119, 853-879. [CrossRef]

60. Cheng, B.S.; Chou, L.F.; Huang, M.P.; Wu, T.Y.; Farh, J.L. Paternalistic leadership and subordinate reverence: Establishing a leadership model in Chinese organizations. Asian J. Soc. Psychol. 2004, 7, 89-117. [CrossRef]

61. Hofstede, G. Lokales Denken, Globales Handeln. InterkulturelleZusammenarbeit und Globales Management; Dtv: München, Germany, 2006.

62. Whitley, R.D. Eastern Asian enterprise structure and the comparative analysis of forms of business organization. Organ. Stud. 1992, 11, 47-74. [CrossRef]

63. Westwood, R.I. Harmony and patriarchy: The culture basis for paternalistic headship among the oversea Chinese. Organ. Stud. 1997, 18, 445-480. [CrossRef]

64. Pedhazur, E.; Schmelkin, L.P. Measurement, Design and Analysis: An Integrated Approach; Lawrence Erlbaum: Hillsdale, NJ, USA, 1991.

65. Podsakoff, P.M.; Organ, D.W. Self-reports in organizational research: Problems and prospects. J. Manag. 1986, 12, 531-544. [CrossRef]

66. Armstrong, J.S.; Overton, T.S. Estimating Nonresponse Bias in Mail Surveys. J. Mark. Res. 1997, 14, $396-402$. [CrossRef]

67. Brislin, R.W. The wording and translation of research instruments. In Field Methods in Cross-Cultural Research; Lonner, W.J., Berry, J.W., Eds.; Sag: Beverly Hills, CA, USA, 1986; pp. 137-164.

68. Deckop, J.R.; Mangel, R.; Cirka, C.C. Getting more than you pay for: Organizational citizenship behavior and pay-for-performance plans. Acad. Manag. J. 1999, 42, 420-428.

69. Mowday, R.; Porter, L.; Steers, R. The measurement of organizational commitment. J. Vocat. Behav. 1979, 14, $224-247$. [CrossRef]

70. Aranya, N.; Pollock, J.; Amernic, J. An examination of professional commitment in public accounting. Account. Organ. Soc. 1981, 6, 271-280. [CrossRef]

71. Kao, R.H. The effects of organizational commitment, professional commitment, and service-oriented organizational citizenship behavior on cross selling involvement for Taiwanese stockbroker. Compr. Res. J. Manag. Bus. Stud. 2015, 3, 9-20.

72. Payne, S.C.; Webber, S.S. Effects of service provider attitudes and employment status on citizenship behaviors and customers' attitudes and loyalty behavior. J. Appl. Psychol. 2006, 91, 365-378. [CrossRef]

73. Bettencourt, L.A.; Gwinner, K.P.; Meuter, M.L. A comparison of attitude, personality, and knowledge predictors of service-oriented organizational citizenship behaviors. J. Appl. Psychol. 2001, 86, $29-41$. [CrossRef]

74. Hsieh, W.C.; Chen, C.H.; Lee, C.C.; Kao, R.H. Work characteristics and police officer's performance: Exploring the moderating effect of social work characteristics and collective efficacy in multilevel analysis. Polic. Int. J. Police Strateg. Manag. 2012, 35, 615-641. [CrossRef]

75. Kakar, S. Self-evaluations of police performance: An analysis of the relationship between police officers' education level and job performance. Polic. Int. J. Police Strateg. Manag. 1998, 21, 632-647. [CrossRef]

76. Schumacker, E.R.; Lomax, G.R. A Beginner's Guide to Structural Equation Modeling; Erlbaum: Mahwah, NJ, USA, 1996.

77. Jöreskog, K.G.; Sörbom, D. LISREL 8 User's Reference Guide; Scientific Software International: Lincolnwood, IL, USA, 1996.

78. Bagozzi, R.P.; Yi, Y. On the evaluation for structural equation models. J. Acad. Mark. Sci. 1988, 16, 74-94. [CrossRef] 
79. Baumgartner, H.; Homburg, C. Applications of structural equation modeling in marketing and consumer research: A review. Int. J. Res. Mark. 1996, 13, 139-161. [CrossRef]

80. Lu, C.S. The impact of carrier service attributes on shipper-carrier partnering relationships: A shipper's perspective. Transp. Res. Part E Logist. Transp. Rev. 2003, 39, 399-415. [CrossRef]

81. Bentler, P.M. Comparative fit indexes in structural models. Psychol. Bull. 1990, 107, 238-246. [CrossRef] [PubMed]

82. Hair, J.F.; Anderson, R.E.; Tatham, R.L.; Black, W.C. Multivariate Data Analysis; Prentice-Hall: Englewood Cliffs, NJ, USA, 1995.

83. Baron, R.M.; Kenny, D.A. The moderator-mediator variable distinction in social psychological research: Conceptual, strategic, and statistical considerations. J. Personal. Soc. Psychol. 1986, 51, 1173-1182. [CrossRef]

84. Hazelzet, E.; Picco, E.; Houkes, I.; Bosma, H.; de Rijk, A. Effectiveness of interventions to promote sustainable employability: A systematic review. Int. J. Environ. Res. Public Health 2019, 16, 1985. [CrossRef] [PubMed]

85. Engelbrecht, A.S.; Heine, G.; Mahembe, B. Integrity, ethical leadership, trust and work engagement. Leadersh. Organ. Dev. J. 2017, 38, 368-379.

86. Smith, D.; Hall, M. An empirical examination of a three-component model of professional commitment among public accountants. Behav. Res. Account. 2008, 20,75-92. [CrossRef]

87. Huang, C.J. A Study on the Relationship between the Education and Training and the Employees' Work Attitudes-The Case in Kaohsiung Harbor Police Annual Subject Training. Master's Thesis, Institute of Business Administration, University of Hsuan, Chuang, Taiwan, 2016. (In Chinese).

88. White, D. A conceptual analysis of the hidden curriculum of police training in England and Wales. Polic. Soc. 2006, 16, 386-404. [CrossRef]

89. Karimi, S.; Biemans, H.J.A.; Lans, T.; Chizari, M.; Mulder, M.; Mahdei, K.N. Understanding role models and gender influences on entrepreneurial intentions among college students. Procedia Soc. Behav. Sci. 2013, 93, 204-214. [CrossRef]

90. Kim, W.; Park, J. Examining structural relationships between work engagement, organizational procedural justice, knowledge sharing, and innovative work behavior for sustainable organizations. Sustainability 2017, 9, 205. [CrossRef]

91. Daft, R.L. Organization Theory and Design; Cengage Learning: South Western, OH, USA, 2001.

92. Hellman, T.; Molin, F.; Svartengren, M. A qualitative study on employees'experiences of a support model for systematic work environment management. Int. J. Environ. Res. Public Health 2019, 16, 3551. [CrossRef]

93. Bolino, M.; Hsiung, H.; Harvey, J.; Lepine, J.A. “Well, I'm tired of trying'!" Organizational citizenship behavior and citizenship fatigue. J. Appl. Psychol. 2015, 100, 56-74. [CrossRef] [PubMed] 